\title{
Association of psychological factors, patients' knowledge, and management among patients with erectile dysfunction
}

This article was published in the following Dove Press journal:

Patient Preference and Adherence

13 May 2016

Number of times this article has been viewed

\author{
Hasniza Zaman Huri, ${ }^{1,2}$ \\ Nurul Diyana Mat Sanusi' \\ Azad Hassan Abdul Razack ${ }^{3}$ \\ Raymond Mark' \\ 'Department of Pharmacy, ${ }^{2}$ Clinical \\ Investigation Center, University of \\ Malaya Medical Centre, ${ }^{3}$ Department \\ of Surgery, Faculty of Medicine, \\ University of Malaya, Kuala Lumpur, \\ Malaysia
}

Background: Erectile dysfunction (ED) is one of the most common health problems in men. ED can significantly affect a man's psychological well-being and overall health.

Purpose: To investigate the association of psychological factors, patients' knowledge, and management among ED patients.

Patients and methods: A total of 93 patients with an age range from 31 to 81 years who have undergone treatment for ED were included in this study.

Results: It was found that the feeling of blame $(P=0.001)$, guilt $(P=0.001)$, anger or bitterness ( $P=0.001)$, depression $(P=0.001)$, feeling like a failure $(P=0.001)$, and the feeling of letting down a partner during intercourse $(P=0.001)$ were significantly associated with ED. Age was also found to be significantly associated with patients' psychological scale $(P=0.004)$. In addition, the majority of patients in this study practice the right method of administration of ED therapy. However, no significant correlation was found between patients' knowledge of ED therapy and demographic characteristics.

Conclusion: This study concluded that ED does affect psychological well-being of people. In addition, patient's knowledge about ED and its management is also crucial in ensuring that the patient achieves optimal therapeutic outcomes from ED therapy.

Keywords: erectile dysfunction, psychological factors, patients' knowledge, management

\section{Introduction}

According to the Diagnostic and Statistical Manual of Mental Disorders (fifth edition), erectile dysfunction (ED) is characterized by a recurrent inability to achieve or maintain an adequate erection during partnered sexual activities. ${ }^{1}$ The causes of ED are multifactorial, which include anatomical, vascular, neurological, hormonal, and psychological factors. ${ }^{2}$ Since it is non-life-threatening, many men take it for granted and leave it undiagnosed and untreated. ${ }^{3}$ In addition, because of the perception of people that ED is a "taboo" subject, patients tend to overlook it from the aspect of health care. ${ }^{4}$ This circumstance might lead to approximately 322 million men worldwide being affected by ED by $2025 .{ }^{5}$ Apart from sexual deterioration, men with ED are more prone to experience psychological distress. ${ }^{6}$ Generally, "psychology" can be defined as "the scientific study of behavior and experience".? Thus, in this context, "psychology" refers to the behavior and experience of patients with ED. The psychological impact of ED can be seen in their current marital relationship, the willingness to discuss ED, the feeling of guilt and denial, depression, anger, decrease in self-confidence and self-esteem, as well as the feeling of failure as a man. ${ }^{8,9}$ The socioeconomic state can also indirectly enhance ED progression
Correspondence: Hasniza Zaman Hur Department of Pharmacy, Faculty of

Medicine, University of Malaya, 50603

Kuala Lumpur, Malaysia

Tel +60 379676659

Fax +60 379674964

Email hasnizazh@um.edu.my
Patient Preference and Adherence 2016:10 807-823

807

Dovepress

http://dx.doi.org/1 $0.2147 /$ PPA.S99544 (c) (1) (5) 2016 Huri et al. This work is published and licensed by Dove Medical Press Limited. The full terms of this license are available at https://www.dovepress.com/terms.php

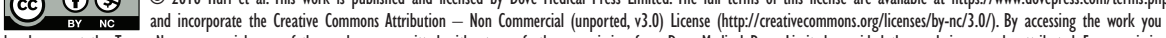
hereby accept the Terms. Non-commercial uses of the work are permitted without any further permission from Dove Medical Press Limited, provided the work is properly attributed. For permission for commercial use of this work, please see paragraphs 4.2 and 5 of our Terms (https://www.dovepress.com/terms.php). 
and might subsequently worsen their psychological well-being. ${ }^{3,8}$ Hence, men with ED are at higher risk of experiencing significant physical and emotional dissatisfaction and a decrease in overall quality of life (QoL) compared to healthy men. ${ }^{6}$ Patients' knowledge about ED and its management is important for the success of therapy. ${ }^{10}$ Many men, especially the elderly, have a misconception about ED being a normal part of aging and leave it untreated. ${ }^{3}$ However, they do not realize that ED can be a strong indicator of coronary vascular disease, especially coronary artery disease. ${ }^{11}$ A realistic expectation from ED therapy is also necessary to ensure compliance and treatment satisfaction. ${ }^{12} \mathrm{~A}$ recent guideline has stated that first-line therapies in the management of ED are sildenafil (Viagra ${ }^{\circledR}$, Pfizer, New York, NY, USA), vardenafil (Levitra ${ }^{\circledR}$, Bayer Health Care Pharmaceuticals, Whippany, NJ, USA), and tadalafil (Cialis ${ }^{\circledR}$, Eli Lilly and Company, Indianapolis, IN, USA), followed by intracavernosal and intraurethral therapy with alprostadil as well as vacuum erection devices as secondline therapy. The third-line treatment and final resolution for ED patient is surgical implantation of a penile prosthesis. ${ }^{2}$ Proper timing of administration of ED therapy is important because improper timing leads to treatment failure and disappointment. ${ }^{13}$ Knowledge of the anticipated side effects of ED therapy is important for therapy compliance, because despite mild adverse effects of oral ED therapy, few of phosphodiesterase type 5 inhibitor (PDE5) inhibitor users withdraw from the therapy due to their unawareness. ${ }^{14}$ The success of ED therapy is important as it will not just improve the man's sexual function but will also indirectly improve psychological and marital relationship as well as his general well-being. ${ }^{15}$

In Malaysia, the current prevalence of ED is high $(69.5 \%)$ despite the advancement in the health care system. ${ }^{16}$ A recent study found that psychological factors of patients have a significant impact on the occurrence of ED. ${ }^{3}$ Another recent study also found that patients' knowledge on the occurrence of ED influences ED management. ${ }^{8}$ In addition, continuous counseling and follow-up by the health care professionals also play an important role in the management of ED.

However, there is limited data on the effect of psychological factors, patients' knowledge, and management of ED. Therefore, the results of this study can be used to enhance the understanding of factors associated with ED. Besides, this study might also help in determining further action, such as increasing the health care professionals' role in educating ED patients to improve patients' knowledge, and hence ED management. The aim of this study was to investigate the association of psychological factors, patients' knowledge, and management among patients with ED.

\section{Patients and methods Study design}

A cross-sectional prospective study was conducted. The data were directly obtained from the results of face-to-face interviews with the patients. The interview was conducted based on the questionnaire adopted. ${ }^{1,17-20}$ The questionnaire was available in both English and Bahasa Malaysia.

\section{Sample population, sampling frame, and sample size}

The sampling populations were adult patients with ED who visited the ED, surgery, eye, or medical clinics at the University of Malaya Medical Centre (UMMC). Convenience sampling was employed to select ED patients during the period from January 2014 to April 2014. The study was carried out after obtaining approval from the Medical Ethics Committee of the UMMC. A total of 93 patients were approached throughout the study period. All the subjects who were included in this study fulfilled the inclusion criteria.

\section{Inclusion and exclusion criteria}

\section{Inclusion criteria}

- Adult male patients aged 18 years and above.

- Patients diagnosed with ED.

- Patients on pharmacological and/or nonpharmacological ED therapy.

\section{Exclusion criteria}

- Patients unwilling to participate in the survey.

- Patients diagnosed with psychiatry illness or mentally retarded.

- Patients undergoing ED surgery.

\section{Data collection}

A questionnaire was developed based on few previous studies. ${ }^{1,17-20}$ The psychological questions were developed by adapting few questions from a survey done by MacDonagh et al. ${ }^{17}$ Upon approval by the Medical Ethics Committee of the UMMC (reference number 1031.11), a pilot study involving ten patients was carried out to validate the questionnaire and to assess the suitability of the questionnaire to patients' understanding. The final version of the questionnaire used in the study was based on the pilot study. Subsequently, patients 
in the emergency department, surgery, eye, and medical clinics at the UMMC were screened based on the inclusion and exclusion criteria. Patients who did not meet the selection criteria were excluded from the study. Once the eligible study population was identified, the patient information sheet to explain the purpose and methodology of the study was given to the patients. In addition, the patients were also assured that their participation would not affect their future medical care and that the information obtained was strictly confidential. Patients who agreed to participate signed a consent form to signify their agreement. A face-to-face interview was conducted with each patient (Figure 1). The data obtained were collected and analyzed.

The questionnaire was developed based on a few previous studies..$^{2,3,5,18-20}$ The questionnaire was made to suit the characteristics of the Malaysian population.
The questionnaire was divided into three sections, and the outline is as follows.

\section{Section A: sociodemographic data}

- Age

- Nationality

- Ethnicity

- Marital status

- Education level

- Occupation

- Type of profession

- Total monthly income.

\section{Section B: psychological factors}

Cognitive psychological scale was measured based on Erectile Dysfunction - Effect on Quality of Life (ED-EqoL), an

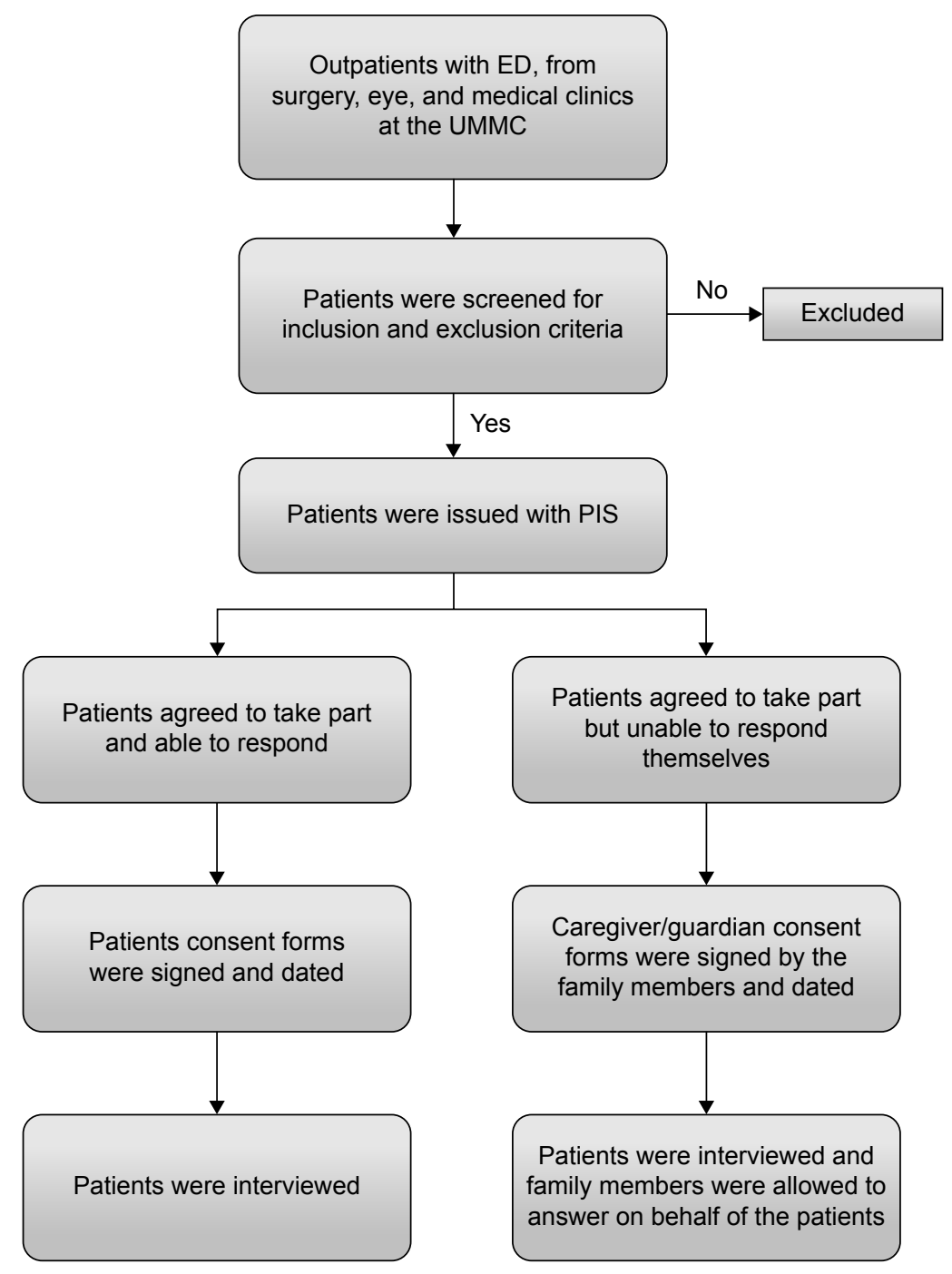

Figure I Overview of study procedure.

Abbreviations: ED, erectile dysfunction; PIS, patient information sheet; UMMC, University of Malaya Medical Centre. 
instrument used to quantify the effect of ED-QoL. Among the questions asked were the following:

- Do you feel that the dissatisfaction toward your household monthly income worsen your ED?

- As a result of erectile difficulties, do you blame yourself for being unable to satisfy your partner?

- Does your inability to produce an erection with your partner make you feel guilty?

- Do you feel less desirable as a result of your erectile difficulties?

- Do you feel hurt by your partner's response to your erectile difficulties?

- Does the fact that you are unable to produce an erection make you feel less a man?

- Do you feel angry or bitter that you cannot produce an erection?

- Do you feel depressed that you cannot produce an erection?

- Is your self-esteem damaged by your erectile problems?

- Do you feel a failure because of your erectile difficulties?

- Do you feel that you had let down your partner by your inability to produce an erection?

- Do you feel worried that your erectile problems have affected the closeness between you and your partner?

- Does your erectile problem make you worry about how your life will develop in the future?

- Are you preoccupied by your erection problems?

Section C: patients' knowledge on ED and its management

- Duration of ED

- Definition of ED
- Cause(s) of ED

- Expected outcome from ED therapy

- Type of treatment

- Oral medication: generic name, administration time, maximum frequency per day, correct way of storage, side effects of medications

- Intracavernosal injection: medication name, right time of injection, correct technique of injection, correct method of storage, side effects of medication

- Intraurethral therapy: medication name, right time of application, maximum frequency per day, correct method of storage, side effects of medication

- Vacuum pump: right time of application, side effects from therapy

- Hormone therapy: name of medication, administration time, maximum frequency per day, side effects from the therapy.

\section{Data analysis}

All the data obtained from the interview were compiled and analyzed using the Statistical Package for Social Sciences version 20.0 (IBM Corporation, Armonk, NY, USA). The details of the definitions used for the purpose of this study are listed in Table 1.

The patients' socioeconomic status was analyzed using descriptive statistics. The descriptive statistics were expressed as frequency $(\mathrm{N}, \%)$ and mean \pm standard deviation .

Meanwhile, the patients' psychology experienced was assessed by using the ED Effect on QoL instruments. ${ }^{17}$ Each psychology question was scored as 0 - not affected at all, 1 - affected a little, or 2 - affected somewhat. The total cumulative score was calculated, and a score of less than 15 indicated that the patient was mildly affected by ED,

Table I Definition

\begin{tabular}{ll}
\hline Questions/terms & Definitions \\
\hline ED-EQoL instrument & An instrument used for quantifying the effect of ED-QoL \\
Psychological scale & $<$ I5: mild impairment of QoL \\
& I5-28: moderate impairment of QoL \\
& $\geq 29:$ severe impairment of QoL \\
& A recurrent inability to achieve or maintain an adequate \\
ED & erection during partnered sexual activities \\
& Improving penile erections suitable for intercourse \\
Expectation from ED therapy & Recommended practice: \\
Time of administration & Sildenafil: Taken approximately I hour before intercourse \\
& Tadalafil: Taken prior to intercourse \\
& Vardenafil: Taken $25-60$ minutes before intercourse \\
Frequency of administration & Recommended practice: take oral ED tablet once daily \\
Storage method & Recommended practice: store the medication at room \\
& temperature $\left(20^{\circ} \mathrm{C}-25^{\circ} \mathrm{C}\right)$
\end{tabular}

Abbreviations: ED, erectile dysfunction; ED-QoL, Erectile Dysfunction-Effect on Quality of Life. 
a score of 15-28 indicated that the patient was moderately affected by ED, and a score of 29 and greater indicated that the patient was severely affected by ED. ${ }^{17}$ The association between psychological factors and ED was assessed by using Pearson's $\chi^{2}$ correlation.

Data on patients' knowledge about ED and its management were collected and analyzed in terms of descriptive and inferential statistics. The descriptive statistics were expressed as frequency $(\mathrm{N}, \%)$ and mean \pm standard deviation. Meanwhile, the associations between patient's knowledge and socioeconomic status were analyzed by using Pearson's $\chi^{2}$ correlation. Fisher's exact test was used when the expected value cell count for greater than $20 \%$ is less than 5 . The results were considered statistically significant if the $P$-value was less than 0.05 . The results obtained are presented in the form of a table and bar chart for a clearer view of the relationship.

\section{Results Study population}

From January 2014 to April 2014, a total of 120 patients were approached. From these 120 patients, 17 respondents were excluded as they did not fulfill the inclusion criteria, while ten respondents did not agree to take part in the study. As a result, only 93 patients were eligible and completed the study. The distribution of patients is shown in Figure 2.

\section{Demographic characteristics}

A total of 93 male patients participated in the study. The majority of the patients were Malay and nonelderly (55.9\%), with mean age of 60.8 years. Most of the participants were currently married (92.5\%), and approximately one-third of the participants had a bachelor degree $(33.3 \%)$. Besides that, more than half of the patients were pensioners (58.1\%), and almost one-third of the patients had a monthly household income

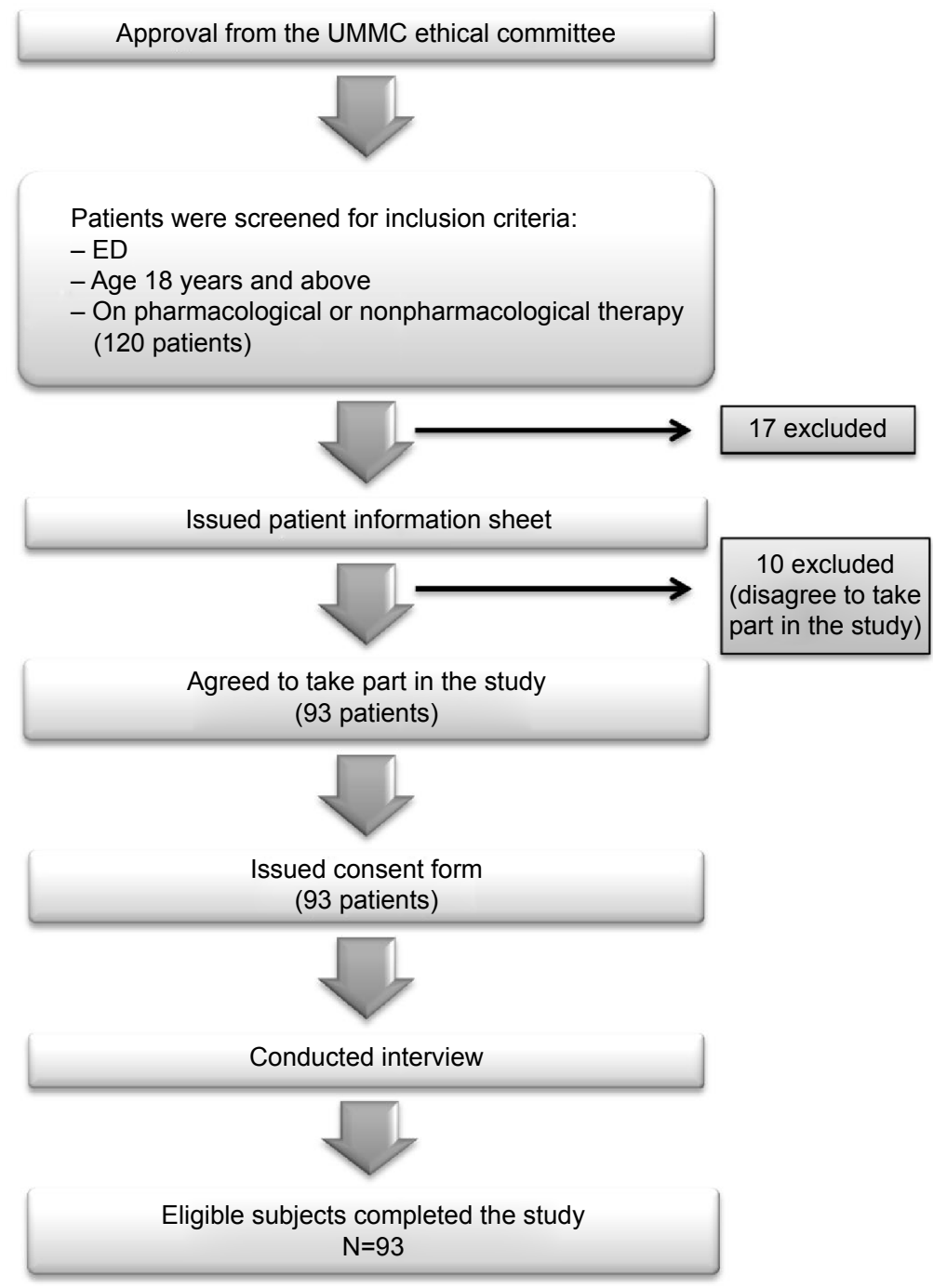

Figure 2 Flowchart of patient disposition.

Abbreviations: ED, erectile dysfunction; UMMC, University of Malaya Medical Centre. 
of RM5,000 or more. The details regarding demographic characteristics of sample study are listed in Table 2.

Table 3 lists the results of the analyses between the duration of ED and patients' demographic characteristics. It showed that only age-group was significantly associated with the duration of ED, while all other variables showed insignificant correlations.

Table 2 Patients' demographic characteristics

\begin{tabular}{|c|c|}
\hline $\begin{array}{l}\text { Demographic } \\
\text { characteristics }\end{array}$ & $\begin{array}{l}\text { Number } \\
\text { of patients }\end{array}$ \\
\hline \multicolumn{2}{|l|}{ Age, years } \\
\hline$<65$ (nonelderly) & $52(55.9)$ \\
\hline$\geq 65$ (elderly) & $41(44.1)$ \\
\hline Mean \pm SD & $60.8 \pm 11.4$ \\
\hline \multicolumn{2}{|l|}{ Ethnicity } \\
\hline Malay & $42(45.2)$ \\
\hline Chinese & $34(36.5)$ \\
\hline Indian & $17(18.3)$ \\
\hline \multicolumn{2}{|l|}{ Marital status } \\
\hline Never married & $\mathrm{I}(\mathrm{I} . \mathrm{I})$ \\
\hline Currently married & $86(92.5)$ \\
\hline Divorced/separated/widower & $6(6.5)$ \\
\hline \multicolumn{2}{|l|}{ Education level } \\
\hline No formal schooling & $0(0)$ \\
\hline Primary school & $2(2.2)$ \\
\hline SRP/PMR/LCE & $4(4.3)$ \\
\hline SPM/MCE/O level & $17(18.3)$ \\
\hline STPM/HSC/A level/certificate & $8(8.6)$ \\
\hline Diploma & $25(26.9)$ \\
\hline Bachelor's degree & $31(33.3)$ \\
\hline Master's degree & $5(5.4)$ \\
\hline $\mathrm{PhD}$ & $\mathrm{I}(\mathrm{I} . \mathrm{I})$ \\
\hline \multicolumn{2}{|l|}{ Occupation } \\
\hline Government employee & $15(16.1)$ \\
\hline Nongovernment employee & $9(9.7)$ \\
\hline Self-employed & $15(16.1)$ \\
\hline Pensioner & $54(58.1)$ \\
\hline Unemployed & $0(0)$ \\
\hline \multicolumn{2}{|l|}{ Types of profession } \\
\hline Professional & $16(17.2)$ \\
\hline Nonprofessional & $22(23.7)$ \\
\hline Not applicable & $55(59.1)$ \\
\hline \multicolumn{2}{|l|}{ Household income } \\
\hline RM0-RM399 & $5(5.4)$ \\
\hline RM400-RM699 & $\mathrm{I}(\mathrm{I} . \mathrm{I})$ \\
\hline RM700-RM999 & $4(4.3)$ \\
\hline RMI,000-RMI,999 & $10(10.8)$ \\
\hline RM2,000-RM2,999 & $17(18.3)$ \\
\hline RM3,000-RM3,999 & $13(14.0)$ \\
\hline RM4,000-RM4,999 & $15(16.1)$ \\
\hline$\geq \mathrm{RM} 5,000$ & $28(30.1)$ \\
\hline
\end{tabular}

Note: Data are reported as number (percentage) unless otherwise stated.

Abbreviations: SD, standard deviation; SRP, Sijil Rendah Pelajaran; PMR, Penilaian Menengah Rendah; LCE, Lower Certificate of Education; SPM, Sijil Pelajaran Malaysia; MCE, Malaysian Certificate of Examination; STPM, Sijil Tinggi Persekolahan Malaysia; HSC, Higher School Certificate.

\section{Association between psychological factors and the ED patient}

The overall psychological scale is listed in Table 4, and the majority of the patients were mildly affected by sexual dysfunction (51.6\%). Figure 3 displays the overall psychological scale in the form of a bar chart.

The associations between patient's psychological scale and psychological factors are listed in Table 5. There were significant correlations between patient's psychological scale and a feeling of blame ( $P=0.001)$, feeling of guilt $(P=0.001)$, feeling of anger or bitterness $(P=0.001)$, depression $(P=0.001)$, feeling like a failure $(P=0.001)$, and feeling of having letting down the partner during intercourse $(P=0.001)$. Other associations were found to be insignificant.

Table 6 lists the association between patient's psychological scale and demographic characteristics. Agegroup was shown to be significantly associated with psychological scale $(P=0.004)$, while others were reported to be insignificant.

\section{Patient's knowledge on ED and its management}

An assessment of patient's knowledge was done, and the results showed that the majority of patients (91.4\%) know ED, which is defined as their inability to achieve or maintain an erection sufficient for satisfactory sexual function. Furthermore, the majority of patients perceived the causes of their ED were due to diseases (27.8\%). An assessment of patients' expectations upon treatment was also done, with most of the patients expecting their penile erections to be improved following treatment (35.5\%) and 33.3\% of patients expecting a total recovery from their ED. In addition, a survey on duration of ED was done, and the results showed that the majority of patients had experienced ED for at least 10 years (34.4\%). The details of patients' knowledge on ED are listed in Table 7. Figure 4 illustrates the causes of ED perceived by patients in a graphical form.

\section{Patients' knowledge on ED treatment}

Most of the patients were on sildenafil $(\mathrm{N}=54)$, followed by tadalafil $(\mathrm{N}=22)$ and vardenafil $(\mathrm{N}=17)$. Detailed medication consumption is shown in Figure 5. A survey on patients' knowledge toward their respective oral therapy was done and is listed in Table 8. A majority of the patients on sidenafil took the medication just before intercourse (50\%). However, for tadalafil users, $36.4 \%$ of the patients took it just before or an hour before sexual intercourse. For vardenafil users, the majority of consumers $(41.2 \%)$ took the medication just 
Table 3 The association between duration of ED and demographic characteristics

\begin{tabular}{|c|c|c|c|c|c|c|c|}
\hline \multirow{2}{*}{$\begin{array}{l}\text { Demographic } \\
\text { characteristics }\end{array}$} & \multicolumn{5}{|c|}{ Duration of ED (years) } & \multirow[t]{2}{*}{ Total } & \multirow[t]{2}{*}{$P$-value } \\
\hline & $<\mathbf{I}$ & $1-3$ & $4-6$ & 7-9 & $\geq 10$ & & \\
\hline \multicolumn{8}{|l|}{ Age-group } \\
\hline$<65$ years & 8 & 11 & 14 & II & 8 & 52 & $0.001 *$ \\
\hline$\geq 65$ years & 0 & 5 & 6 & 6 & 24 & 41 & \\
\hline \multicolumn{8}{|l|}{ Ethnicity } \\
\hline Malay & 4 & 5 & 12 & 9 & 12 & 42 & 0.333 \\
\hline Chinese & 1 & 8 & 6 & 4 & 15 & 34 & \\
\hline Indian & 3 & 3 & 2 & 4 & 5 & 17 & \\
\hline \multicolumn{8}{|l|}{ Marital status } \\
\hline Unmarried & 0 & 0 & 0 & 0 & 1 & 1 & 0.929 \\
\hline Currently married & 8 & 15 & 19 & 16 & 28 & 86 & \\
\hline Divorced/widower & 0 & 1 & 1 & 1 & 3 & 6 & \\
\hline \multicolumn{8}{|l|}{ Educational level } \\
\hline Primary & 1 & 0 & 0 & 0 & 1 & 2 & 0.294 \\
\hline Secondary & 3 & 2 & 4 & 6 & 6 & 21 & \\
\hline Tertiary & 4 & 14 & 16 & 11 & 25 & 70 & \\
\hline \multicolumn{8}{|l|}{ Occupation } \\
\hline Government employee & 5 & 4 & 4 & 2 & 0 & 15 & $0.00 I^{a}$ \\
\hline Nongovernment employee & 2 & 1 & 3 & 2 & 1 & 9 & \\
\hline Self-employed & 1 & 7 & 6 & 1 & 0 & 15 & \\
\hline Pensioner & 0 & 4 & 7 & 12 & 31 & 54 & \\
\hline \multicolumn{8}{|l|}{ Household income } \\
\hline$<$ RM5,000 & 5 & 10 & 12 & 14 & 24 & 65 & 0.524 \\
\hline$\geq$ RM5,000 & 3 & 6 & 8 & 3 & 8 & 28 & \\
\hline
\end{tabular}

Notes: $\chi^{2}$ test was done to obtain the $P$-value; ${ }^{*} P$-value was significant $(P<0.05)$; ${ }^{P}$-value was not reliable due to more than $20 \%$ of the cells have expected frequencies that are less than 5 .

Abbreviation: ED, erectile dysfunction.

before intercourse. In terms of medication frequency, majority of sildenafil, tadalafil, and vardenafil users took the medication once daily, $57.4 \%, 63.6 \%$, and $58.8 \%$, respectively. Furthermore, more than $70 \%$ of patients stored the medication at room temperature. A survey on side effects was done, and the results showed that sildenafil and tadalafil users were more likely to experience facial flushing and dizziness, while vardenafil users were more likely to experience dizziness and back pain. However, the majority of oral therapy users did not experience any side effects. Furthermore, the majority of oral therapy users knew the possible side effects of their medications. The patient's knowledge regarding their treatment is listed in Table 8. Table 9 lists the overall results of patient's knowledge about ED therapy.

Table 10 lists the $\chi^{2}$ analyses between patients' educational level and knowledge on ED. There was no significant

Table 4 Overall psychological scales

\begin{tabular}{ll}
\hline Psychological scale & Number of patients \\
\hline Mild & $48(51.6)$ \\
Moderate & $28(30.1)$ \\
Severe & $17(18.3)$ \\
\hline
\end{tabular}

Note: Data are reported as number (percentage). correlation found between educational level and patient's knowledge on ED. Table 11 lists the results of association between occupation and patient's knowledge on ED, and there was no association obtained between these two parameters. Table 12 shows the results of association between household income and patient's knowledge on ED. However, there was no significant association found between these two parameters.

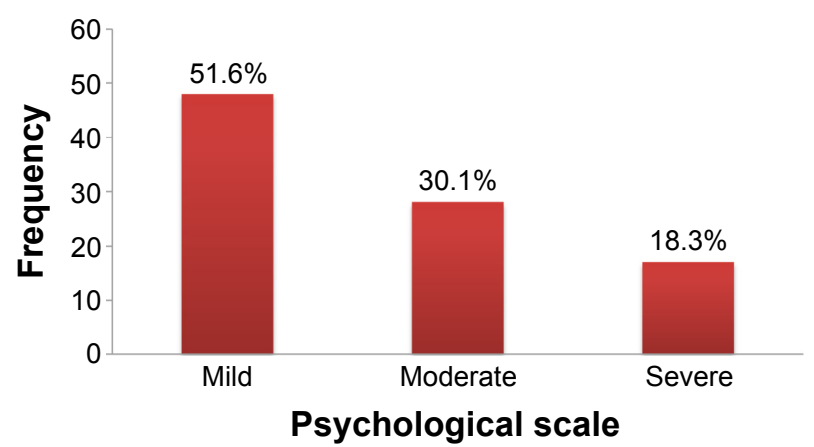

Figure 3 Overall psychological score rated by patients.

Note: Frequency refers to number of ED patients affected by ED and classified as mild, moderate and severe.

Abbreviation: ED, erectile dysfunction. 
Table 5 Psychological factors associated with ED patients

\begin{tabular}{|c|c|c|c|c|c|c|}
\hline \multirow{2}{*}{$\begin{array}{l}\text { Psychological } \\
\text { factors }\end{array}$} & \multicolumn{3}{|c|}{ Psychological scale } & \multirow[t]{2}{*}{ Total } & \multirow[t]{2}{*}{$\chi^{2}$} & \multirow[t]{2}{*}{ P-value } \\
\hline & Mild & Moderate & Severe & & & \\
\hline \multicolumn{7}{|c|}{ Dissatisfaction on household income } \\
\hline Not at all & 43 & 18 & 6 & 67 & 35.201 & $0.00 \mathrm{I}^{\mathrm{a}}$ \\
\hline A little & 5 & 8 & 3 & 16 & & \\
\hline Somewhat & 0 & 2 & 8 & 10 & & \\
\hline \multicolumn{7}{|l|}{ Blame themselves } \\
\hline Not at all & 32 & 5 & 0 & 37 & 48.500 & $0.001 *$ \\
\hline A little & 13 & 10 & 2 & 25 & & \\
\hline Somewhat & 3 & 13 & 15 & 31 & & \\
\hline \multicolumn{7}{|l|}{ Feelings of guilt } \\
\hline Not at all & 31 & 5 & 0 & 36 & 57.508 & $0.001 *$ \\
\hline A little & 16 & 6 & I & 23 & & \\
\hline Somewhat & 1 & 17 & 16 & 34 & & \\
\hline \multicolumn{7}{|l|}{ Less desirable } \\
\hline Not at all & 41 & 6 & 0 & 48 & 72.162 & $0.00 I^{\mathrm{a}}$ \\
\hline A little & 7 & 13 & 2 & 28 & & \\
\hline Somewhat & 0 & 9 & 15 & 17 & & \\
\hline \multicolumn{7}{|l|}{ Feeling hurt } \\
\hline Not at all & 38 & II & 0 & 49 & 45.277 & $0.00 I^{a}$ \\
\hline A little & 8 & 7 & 3 & 18 & & \\
\hline Somewhat & 2 & 10 & 14 & 26 & & \\
\hline \multicolumn{7}{|l|}{ Feel "less a man" } \\
\hline Not at all & 11 & 1 & I & 48 & 28.305 & $0.00 I^{\mathrm{a}}$ \\
\hline A little & 17 & I & 0 & 28 & & \\
\hline Somewhat & 20 & 26 & 16 & 17 & & \\
\hline \multicolumn{7}{|l|}{ Angry or bitter } \\
\hline Not at all & 32 & 3 & 0 & 35 & 57.185 & $0.001 *$ \\
\hline A little & 12 & 9 & 0 & 21 & & \\
\hline Somewhat & 4 & 16 & 17 & 37 & & \\
\hline \multicolumn{7}{|l|}{ Depression } \\
\hline Not at all & 31 & 0 & 0 & 31 & 62.147 & $0.001 *$ \\
\hline A little & 12 & 9 & 0 & 21 & & \\
\hline Somewhat & 5 & 19 & 17 & 41 & & \\
\hline \multicolumn{7}{|l|}{ Low self-esteem } \\
\hline Not at all & 26 & I & 0 & 27 & 61.140 & $0.001 *$ \\
\hline A little & 19 & 8 & 0 & 27 & & \\
\hline Somewhat & 3 & 19 & 17 & 39 & & \\
\hline \multicolumn{7}{|l|}{ Feel like a failure } \\
\hline Not at all & 35 & 3 & 0 & 38 & 60.908 & $0.001 *$ \\
\hline A little & 11 & 9 & I & 21 & & \\
\hline Somewhat & 2 & 16 & 16 & 34 & & \\
\hline \multicolumn{7}{|c|}{ Feel had let down partner } \\
\hline Not at all & 26 & 0 & 0 & 26 & 60.561 & $0.001 *$ \\
\hline A little & 18 & 11 & 0 & 29 & & \\
\hline Somewhat & 4 & 17 & 17 & 38 & & \\
\hline \multicolumn{7}{|c|}{ Worry ED will affect closeness with partner } \\
\hline Not at all & 40 & 13 & 0 & 53 & 67.632 & $0.00 I^{\mathrm{a}}$ \\
\hline A little & 7 & 10 & I & 18 & & \\
\hline Somewhat & 1 & 5 & 16 & 22 & & \\
\hline Worry for futur & & & & & & \\
\hline Not at all & 43 & 17 & 1 & 61 & 64.131 & $0.00 I^{\mathrm{a}}$ \\
\hline A little & 4 & 6 & 0 & 10 & & \\
\hline Somewhat & I & 5 & 16 & 22 & & \\
\hline Preoccupied witl & & & & & & \\
\hline Not at all & 26 & 0 & 0 & 48 & 58.055 & $0.00 I^{\mathrm{a}}$ \\
\hline A little & 17 & 10 & 0 & 28 & & \\
\hline Somewhat & 5 & 18 & 17 & 17 & & \\
\hline
\end{tabular}

Notes: $\chi^{2}$ test was done to obtain the $P$-value; ${ }^{P}$-value was not reliable due to more than $20 \%$ of the cells have expected frequencies that are less than 5 ; ${ }^{*} P$-value was significant $(P<0.05)$.

Abbreviation: ED, erectile dysfunction. 
Table 6 The association between psychological scale and demographic characteristics

\begin{tabular}{|c|c|c|c|c|c|c|}
\hline \multirow{2}{*}{$\begin{array}{l}\text { Demographic } \\
\text { characteristics }\end{array}$} & \multicolumn{3}{|c|}{ Psychological scale } & \multirow[t]{2}{*}{ Total } & \multirow[t]{2}{*}{$x^{2}$} & \multirow[t]{2}{*}{$P$-value } \\
\hline & Mild & Moderate & Severe & & & \\
\hline \multicolumn{7}{|l|}{ Age-group } \\
\hline$<65$ years & 19 & 20 & 13 & 52 & 10.841 & $0.004^{*}$ \\
\hline$\geq 65$ years & 29 & 8 & 4 & 41 & & \\
\hline \multicolumn{7}{|l|}{ Ethnicity } \\
\hline Malay & 19 & 12 & 11 & 42 & 4.658 & 0.324 \\
\hline Chinese & 20 & 9 & 5 & 34 & & \\
\hline Indian & 9 & 7 & I & 17 & & \\
\hline \multicolumn{7}{|l|}{ Marital status } \\
\hline Unmarried & 1 & 0 & 0 & I & 7.097 & 0.131 \\
\hline Currently married & 41 & 28 & 17 & 86 & & \\
\hline Divorced/widowed & 6 & 0 & 0 & 6 & & \\
\hline \multicolumn{7}{|l|}{ Occupation } \\
\hline Government employee & 3 & 6 & 6 & 15 & 18.483 & $0.005^{\mathrm{a}}$ \\
\hline Nongovernment employee & 3 & 2 & 4 & 9 & & \\
\hline Self-employed & 6 & 6 & 3 & 15 & & \\
\hline Pensioner & 36 & 14 & 4 & 54 & & \\
\hline \multicolumn{7}{|l|}{ Educational level } \\
\hline Primary & 1 & 0 & I & 2 & 3.312 & 0.507 \\
\hline Secondary & 13 & 6 & 2 & 21 & & \\
\hline Tertiary & 34 & 22 & 14 & 70 & & \\
\hline \multicolumn{7}{|l|}{ Household income } \\
\hline$<$ RM5,000 & 36 & 20 & 9 & 65 & 2.948 & 0.229 \\
\hline$\geq \mathrm{RM} 5,000$ & 12 & 8 & 8 & 28 & & \\
\hline
\end{tabular}

Notes: $\chi^{2}$ test was done to obtain the $P$-value; ${ }^{*} P$-value was significant $(P<0.05)$; ${ }^{a}$-value was not reliable due to more than $20 \%$ of the cells have expected frequencies that are less than 5 .

Table 7 Patients' knowledge about ED and its occurrence

\begin{tabular}{ll}
\hline ED knowledge & $\begin{array}{l}\text { Number } \\
\text { of patients }\end{array}$ \\
\hline How long you experienced ED? & $8(8.6)$ \\
Less than a year & $16(17.2)$ \\
I-3 years & $20(21.5)$ \\
4-6 years & $17(18.3)$ \\
$7-9$ years & $32(34.4)$ \\
I0 years and more & \\
What is ED? & $85(91.4)$ \\
Inability to achieve or maintain an erection & \\
sufficient for satisfactory sexual function & $7(7.5)$ \\
ED is defined as complete impotence & $1(1.1)$ \\
Do not know & \\
Causes of ED & $18(18.6)$ \\
Aging & $27(27.8)$ \\
Diseases & $12(12.4)$ \\
Medications & $1(1.0)$ \\
Surgery & $9(9.3)$ \\
Lifestyle & $10(10.3)$ \\
Psychological factors & $4(4.1)$ \\
Socioeconomic factors & $16(16.5)$ \\
Do not know & \\
Most expected outcome from ED treatment & $31(33.3)$ \\
Total recovery from ED & $33(35.5)$ \\
Improving penile erections suitable for & \\
intercourse & $9(9.7)$ \\
Feeling of satisfaction during intercourse & $4(4.3)$ \\
Spouse satisfaction during intercourse & $16(17.2)$ \\
Do not know & \\
\hline Note Data are &
\end{tabular}

Note: Data are reported as number (percentage).

Abbreviation: ED, erectile dysfunction.

\section{Discussion}

\section{Demographic characteristics}

The association between age and ED

The study showed a strong correlation between age-group and duration of ED. The finding was consistent with a study done in an urban setting in Malaysia, which reported the increased prevalence of ED with age ${ }^{16}$ Furthermore, a study done in Asian countries reported a pooled random effect of age-specific prevalence rate of approximately $15 \%$ and $70 \%$ for men aged between 20-29 and 60-69 years, respectively. ${ }^{21}$ Hence, the prevalence of ED does increase with aging. The

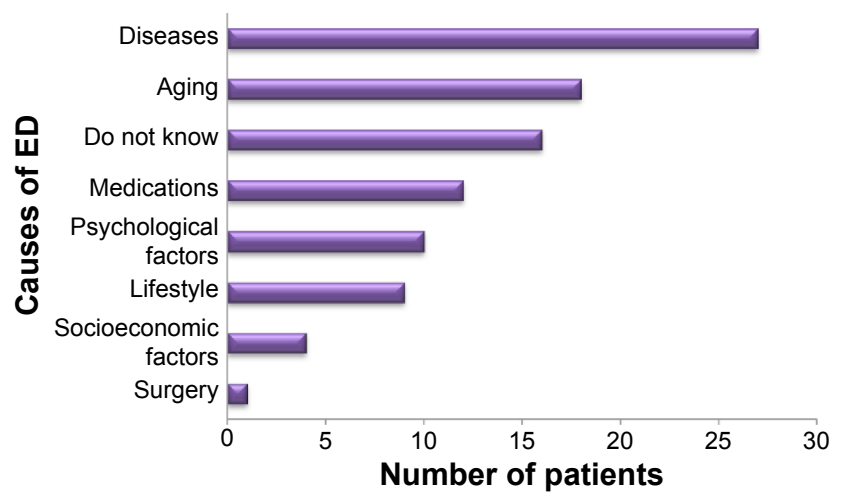

Figure 4 Causes of ED as perceived by patients. Abbreviation: ED, erectile dysfunction. 


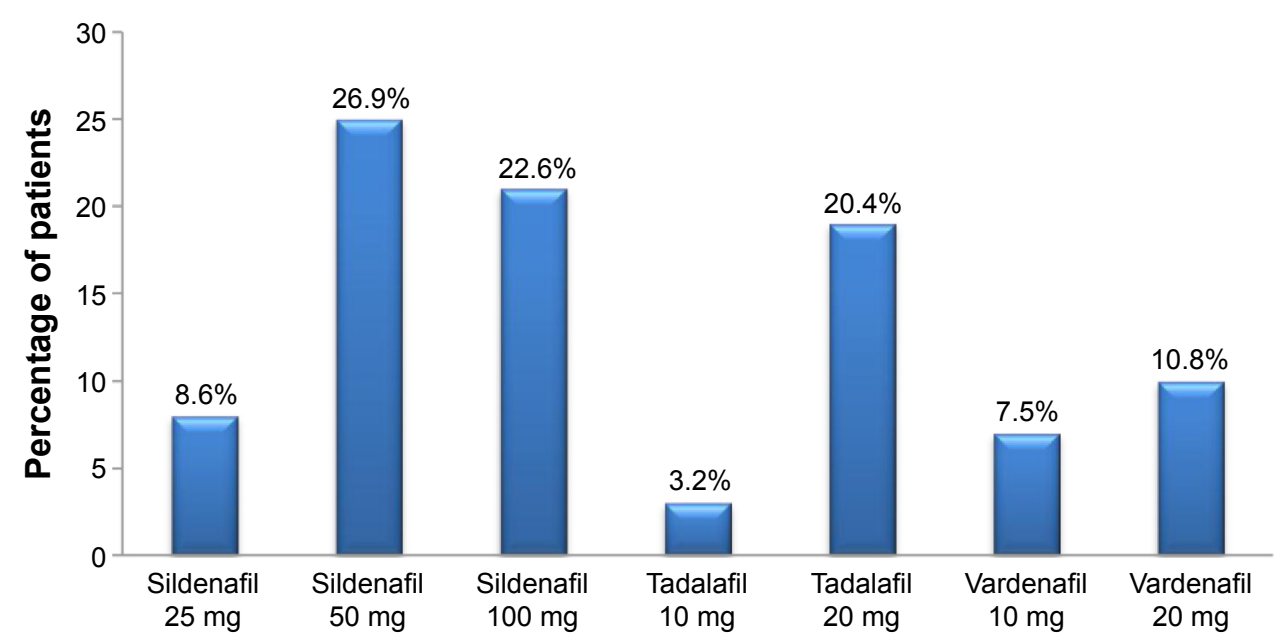

Medication name

Figure $\mathbf{5}$ Type of medication taken by the study population.

occurrence is most likely due to a gradual decrease in physiological function of a person as a person ages. It is expected that ED will become a major problem in the future as the elderly population is growing year by year.
The association between ethnicity and ED

The analysis showed that the majority of patients were Malay, followed by Chinese and Indians, with percentage of $45.2 \%$, $36.5 \%$, and $18.3 \%$ respectively. However, there was no

Table 8 Knowledge of patient on ED treatment

\begin{tabular}{|c|c|c|c|}
\hline ED knowledge & $\begin{array}{l}\text { Sildenafil } \\
(\mathrm{N}=54)\end{array}$ & $\begin{array}{l}\text { Tadalafil } \\
(\mathrm{N}=22)\end{array}$ & $\begin{array}{l}\text { Vardenafil } \\
(\mathrm{N}=17)\end{array}$ \\
\hline \multicolumn{4}{|l|}{ When to take ED medication } \\
\hline Just before sexual activity & $19(35.2)$ & $8(36.4)$ & $7(4 \mid .2)$ \\
\hline I hour before sexual activity & $27(50.0)$ & $8(36.4)$ & $6(35.3)$ \\
\hline $3-4$ hours before sexual activity & $0(0)$ & I (4.5) & $0(0)$ \\
\hline Anytime preferable & $3(5.6)$ & $2(9.1)$ & $2(I I .8)$ \\
\hline Do not know & $5(9.3)$ & $3(13.6)$ & $2(I 1.8)$ \\
\hline \multicolumn{4}{|l|}{ Maximum frequency in a day } \\
\hline Once daily & $31(57.4)$ & $14(63.6)$ & $10(58.8)$ \\
\hline Twice daily & $10(18.5)$ & I (4.5) & $6(35.3)$ \\
\hline Three times daily & $\mathrm{I}(\mathrm{I} .9)$ & $0(0)$ & $0(0)$ \\
\hline More than 3 times daily & $0(0)$ & $0(0)$ & $0(0)$ \\
\hline Do not know & $12(22.2)$ & $7(31.8)$ & I (5.9) \\
\hline \multicolumn{4}{|l|}{ Correct way of medication storage } \\
\hline Store in refrigerator $\left(0^{\circ} \mathrm{C}-4^{\circ} \mathrm{C}\right)$ & $12(22.2)$ & $5(22.7)$ & $5(29.4)$ \\
\hline Store at room temperature $\left(20^{\circ} \mathrm{C}-25^{\circ} \mathrm{C}\right)$ & $42(77.8)$ & $17(77.3)$ & $12(70.6)$ \\
\hline Do not know & $0(0)$ & $0(0)$ & $0(0)$ \\
\hline \multicolumn{4}{|l|}{ Experiencing side effects of medication } \\
\hline Indigestion & $3(3.9)$ & $0(0)$ & $3(12.0)$ \\
\hline Nausea & $\mathrm{I}(\mathrm{I} .3)$ & $0(0)$ & I (4.0) \\
\hline Vomiting & $3(3.9)$ & $0(0)$ & I (4.0) \\
\hline Facial flushing & $15(19.5)$ & $9(29.0)$ & $2(8.0)$ \\
\hline Dizziness & $19(24.7)$ & $7(22.6)$ & $4(16.0)$ \\
\hline Muscle pain & $2(2.6)$ & $3(9.7)$ & $3(12.0)$ \\
\hline Back pain & $7(9.1)$ & $2(6.4)$ & $4(16.0)$ \\
\hline Visual disturbances & $\mathrm{I}(\mathrm{I} .3)$ & $0(0)$ & $0(0)$ \\
\hline Nasal congestion & $\mathrm{I}(\mathrm{I} .3)$ & $0(0)$ & $0(0)$ \\
\hline Do not experience & $25(32.5)$ & $10(32.3)$ & $7(28.0)$ \\
\hline \multicolumn{4}{|l|}{ Knowing it has side effect } \\
\hline Yes & $35(64.8)$ & $14(63.6)$ & $10(58.8)$ \\
\hline No & $19(35.2)$ & $8(36.4)$ & $7(4 \mid .2)$ \\
\hline
\end{tabular}

Note: Data are reported as number (percentage).

Abbreviation: ED, erectile dysfunction. 
Table 9 The overall results of patient's knowledge of ED therapy

\begin{tabular}{ll}
\hline ED knowledge & $\begin{array}{l}\text { Number } \\
\text { of patients }\end{array}$ \\
\hline $\begin{array}{l}\text { Definition of ED } \\
\text { Correct }\end{array}$ & $85(91.4)$ \\
Incorrect & $8(8.6)$ \\
Expectation from ED therapy & \\
$\quad$ Correct & $33(35.5)$ \\
Incorrect & $60(64.5)$ \\
Time of administration & \\
$\quad$ Correct & $42(45.2)$ \\
Incorrect & $51(54.8)$ \\
Frequency of administration & \\
$\quad$ Correct & $55(59.1)$ \\
Incorrect & $38(40.9)$ \\
Storing method & \\
$\quad$ Correct & $71(76.3)$ \\
Incorrect & $22(23.7)$ \\
Knowledge about side effects & \\
Yes & $59(63.4)$ \\
No & $34(36.6)$ \\
\hline
\end{tabular}

Note: Data are presented as number (percentage).

Abbreviation: ED, erectile dysfunction.

significant association between ethnicity and ED. These findings were consistent with a finding of a cross-sectional study done on ED patients by Khoo et al, ${ }^{22}$ although it reported the occurrence of ED was $76.7 \%$ Malay, $70.5 \%$ Chinese, $79.3 \%$ Indians, and $66.7 \%$ in those of others ethnicities. However, these findings were in contrast to a study done by Tan et al, ${ }^{23}$ which reported that the presence of significant association between ED and ethnicity was higher among Malay and
Indians than Chinese. ${ }^{23}$ Another recent study done in Malaysia also reported a significant association between ethnicity and sexual activity. ${ }^{24}$ This explains that there is a possible association between ethnicity and ED. However, the insignificant association in this study might be due to insufficient sample size in ensuring statistical power, because the study conducted by Tan et $\mathrm{al}^{23}$ and Momtaz et $\mathrm{al}^{24}$ had a sample size of 1,046 and 1,036 men, respectively. In addition, the diverse genetic makeup among different ethnicities might limit the possibility of modeling the association between ethnicity and ED adequately.

\section{The association between educational level and} household income with ED

Besides ethnicity, educational level and household income were also found to be insignificantly associated with ED. These findings were consistent with a study done on ED patients in an urban area. ${ }^{22}$ However, recent studies done in Malaysia reported a significant correlation between educational achievement and ED as well as between household income and ED. ${ }^{24}$ It is believed that a well-educated person is more likely to be well paid, having better access to health care centers, and subsequently living a more positive lifestyle. ${ }^{24,25}$ Although this study was conducted in an urban setting where the majority of the participants had at least a bachelor's degree $(33.3 \%)$ or diploma qualifications $(26.9 \%)$ and had a household monthly income of RM5,000 or more (30.1\%), sexual dysfunction still occurred among patients. The possible reason for this occurrence might be due to the fact that

Table 10 The association between educational level and patient's knowledge about ED

\begin{tabular}{|c|c|c|c|c|c|c|}
\hline \multirow[t]{2}{*}{ ED knowledge } & \multicolumn{3}{|c|}{ Educational level } & \multirow[t]{2}{*}{ Total } & \multirow[t]{2}{*}{$\chi^{2}$} & \multirow[t]{2}{*}{$P$-value } \\
\hline & Primary & Secondary & Tertiary & & & \\
\hline \multicolumn{7}{|l|}{ Definition of ED } \\
\hline Correct & 2 & 20 & 63 & 85 & 0.756 & 0.685 \\
\hline Incorrect & 0 & 1 & 7 & 8 & & \\
\hline \multicolumn{7}{|c|}{ Expectation from ED therapy } \\
\hline Correct & 0 & 6 & 27 & 33 & 1.830 & 0.401 \\
\hline Incorrect & 2 & 15 & 43 & 60 & & \\
\hline \multicolumn{7}{|c|}{ Time of administration } \\
\hline Correct & 2 & 9 & 31 & 42 & 2.495 & 0.287 \\
\hline Incorrect & 0 & 12 & 39 & 51 & & \\
\hline \multicolumn{7}{|c|}{ Frequency of administration } \\
\hline Correct & 2 & 11 & 42 & 55 & 1.800 & 0.407 \\
\hline Incorrect & 0 & 10 & 28 & 38 & & \\
\hline \multicolumn{7}{|l|}{ Storing method } \\
\hline Correct & 2 & 16 & 53 & 71 & 0.635 & 0.728 \\
\hline Incorrect & 0 & 5 & 17 & 22 & & \\
\hline \multicolumn{7}{|c|}{ Knowledge about side effects } \\
\hline Yes & I & 10 & 48 & 59 & 3.217 & 0.200 \\
\hline No & I & II & 22 & 34 & & \\
\hline
\end{tabular}

Note: $\chi^{2}$ test was done to obtain the $P$-value.

Abbreviation: ED, erectile dysfunction. 
Table II The association between occupation and patient's knowledge about ED

\begin{tabular}{|c|c|c|c|c|c|c|}
\hline \multirow[t]{2}{*}{ ED knowledge } & \multicolumn{4}{|l|}{ Occupation } & \multirow[t]{2}{*}{ Total } & \multirow[t]{2}{*}{$P$-value } \\
\hline & Government & Nongovernment & Self-employed & Pensioner & & \\
\hline \multicolumn{7}{|l|}{ Definition of ED } \\
\hline Correct & 15 & 9 & 15 & 46 & 85 & $0.097^{a}$ \\
\hline Incorrect & 0 & 0 & 0 & 8 & 8 & \\
\hline \multicolumn{7}{|c|}{ Expectation from ED therapy } \\
\hline Correct & 4 & 4 & 4 & 21 & 33 & 0.658 \\
\hline Incorrect & 11 & 5 & 11 & 33 & 60 & \\
\hline \multicolumn{7}{|c|}{ Time of administration } \\
\hline Correct & 7 & 5 & 10 & 20 & 42 & 0.200 \\
\hline Incorrect & 8 & 4 & 5 & 34 & 51 & \\
\hline \multicolumn{7}{|c|}{ Frequency of administration } \\
\hline Correct & 8 & 3 & $\mathrm{II}$ & 33 & 55 & 0.259 \\
\hline Incorrect & 7 & 6 & 4 & 21 & 38 & \\
\hline \multicolumn{7}{|l|}{ Storing method } \\
\hline Correct & 14 & 7 & 13 & 37 & 71 & 0.163 \\
\hline Incorrect & I & 2 & 2 & 17 & 22 & \\
\hline \multicolumn{7}{|c|}{ Knowledge about side effects } \\
\hline Yes & 10 & 7 & 12 & 30 & 59 & 0.252 \\
\hline No & 5 & 2 & 3 & 24 & 34 & \\
\hline
\end{tabular}

Notes: $\chi^{2}$ test was done to obtain the $P$-value; ${ }^{a} P$-value was not reliable due to more than $20 \%$ of the cells have expected frequencies that are less than 5 .

Abbreviation: ED, erectile dysfunction.

the majority of sample patients were of advanced age, with a mean age of 60.8 years, who mostly had experienced ED for 10 years or more $(34.4 \%)$. Thus, a more comprehensive study should be conducted, which should involve an equal distribution of all ages to obtain a more conclusive finding.

\section{Psychological factors}

Studies have shown that sexual dysfunction can significantly affect men's self-esteem, confidence, and relationship. ${ }^{26}$ A normal sexual function is one of the basic fundamental identity of men, and its deterioration can indirectly affect

Table 12 The association between household income and patient's knowledge about ED

\begin{tabular}{|c|c|c|c|c|c|}
\hline \multirow[t]{2}{*}{ ED knowledge } & \multicolumn{2}{|c|}{ Household income (RM) } & \multirow[t]{2}{*}{ Total } & \multirow[t]{2}{*}{$\chi^{2}$} & \multirow[t]{2}{*}{$P$-value } \\
\hline & $<\mathbf{5 , 0 0 0}$ & $\geq \mathbf{5 , 0 0 0}$ & & & \\
\hline \multicolumn{6}{|l|}{ Definition of ED } \\
\hline Correct & 58 & 27 & 85 & 1.290 & 0.241 \\
\hline Incorrect & 7 & 1 & 8 & & \\
\hline \multicolumn{6}{|c|}{ Expectation from ED therapy } \\
\hline Correct & 23 & 10 & 33 & 0.001 & 0.976 \\
\hline Incorrect & 42 & 18 & 60 & & \\
\hline \multicolumn{6}{|c|}{ Time of administration } \\
\hline Correct & 27 & 15 & 42 & 1.144 & 0.285 \\
\hline Incorrect & 38 & 13 & 51 & & \\
\hline \multicolumn{6}{|c|}{ Frequency of administration } \\
\hline Correct & 38 & 17 & 55 & 0.041 & 0.839 \\
\hline Incorrect & 27 & 11 & 38 & & \\
\hline \multicolumn{6}{|l|}{ Storing method } \\
\hline Correct & 46 & 25 & 71 & 3.715 & 0.054 \\
\hline Incorrect & 19 & 3 & 22 & & \\
\hline \multicolumn{6}{|c|}{ Knowledge about side effects } \\
\hline Yes & 37 & 22 & 59 & 3.954 & $0.057^{\mathrm{a}}$ \\
\hline No & 28 & 6 & 34 & & \\
\hline
\end{tabular}

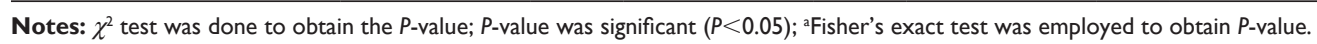

Abbreviation: ED, erectile dysfunction. 
their psychological well-being. Thus, failing in producing and maintaining a sufficient erection during intercourse can significantly affect men's overall health and QoL. ${ }^{15}$

The overall psychological scales showed that the majority of the participants $(51.6 \%)$ were mildly affected by ED. Most of them felt angry, bitter and, depressed because of ED. This indicates that ED can affect psychological well-being of a person. Recent guidelines recommended the combination of psychoeducation and ED therapy to be conducted among men with ED. ${ }^{2}$ Psychoeducation might help to resolve psychological problems encountered by ED patients. In addition, a study reported more positive outcomes, and lesser tendency of dropout among men who received both psychotherapy and oral ED therapy compared to those who were only on oral ED therapy. ${ }^{1}$ Thus, psychologists can play a role in the management of ED, apart from physicians, by helping men with ED to confront with their psychological issues where neither oral therapy nor surgical procedure can fully combat it.

\section{The association between depression and ED}

The study showed a significant correlation between ED and depression. This finding was consistent with a worldwide study done in Brazil, Italy, Japan, and Malaysia, which reported the presence of a strong link between depression and sexual dysfunction, with the occurrence of depression being twice as high in men with ED compared to healthy men. ${ }^{21}$ In addition, a recent study also reported a significant correlation between depression and ED. ${ }^{27}$ The occurrence of depression is mainly because of the fact that penile erection is a sign of manhood in man. Any decline in penile erection will mean a decline in manliness. This might subsequently lead to the feeling of "worthlessness" and might aggravate the current depressive symptoms. However, an appropriate treatment of ED might help in alleviating both ED and depressive symptoms. ${ }^{28}$ Thus, men with ED should seek treatment to improve his sexual dysfunction as well as their psychological well-being.

\section{The association between ED and feeling of anger or bitterness}

The study showed a significant relationship between sexual dysfunction and feeling of anger or bitterness. This finding was consistent with prospective results from the Massachusetts Male Aging Study. ${ }^{29}$ The feeling of anger or bitterness toward themselves results from their disability to produce a sufficient erection during intercourse. ${ }^{29}$ Delay in seeking treatment might result in poor sexual satisfaction for both the man and his partner, which subsequently might lead to a decrease in sexual intimacy and QoL. ${ }^{30}$ Thus, the sexual dysfunction condition should be treated immediately upon its occurrence to benefit of both man and his spouse.

\section{The association between ED and feeling of guilt and failure as a man}

The majority of patients were married at the time (92.5\%). The results showed a significant relationship between ED and the feeling of guilt, blaming oneself as well as the feeling of letting down the partner during intercourse. The study also showed a significant relationship between ED and the feeling of failure as a man. This feeling might lead to loss of self-confidence and self-esteem and might subsequently cause relationship problems. ${ }^{15}$ The continuous feelings of negativity will lead to less frequent sexual intimacy and might indirectly increase the tensions between the couple. ${ }^{31}$ The lack of sexual intimacy can further enhance relationship dissatisfaction among couples. ${ }^{31}$ It was reported that more than one-fifth of men with ED had gone through a divorce due to this sexual dysfunction. ${ }^{30}$ This shows that the way men react to ED and their willingness to discuss it with their spouse play an important role in maintaining one's relationship. Furthermore, their willingness to seek treatment might improve their erections, helps in attempting a successful intercourse, and indirectly improves their marital relationship. A significantly higher relationship satisfaction was seen in women who had ED partners who had undergone treatment for the disease compared to those whose partners had not undergone treatment. ${ }^{32}$ Thus, one's marriage can be maintained through the honesty and openness of the husband with ED discussing the problem with his spouse as well as his willingness to seek treatment as early as possible.

\section{The association between ED and marital relationship} Despite a published study reporting the high probability of future relationship problem due to $\mathrm{ED},{ }^{32}$ this study showed an insignificant correlation between ED and the feeling of worry that ED will affect their current and future relationship. This finding was consistent with a study done by Dunn et al, ${ }^{33}$ which also found an insignificant correlation between marital relationship and ED. The possible explanation can be that the majority of patients in this study were of advanced age, with a mean age of 60.8 years. ${ }^{33}$ Their marital relationship might be more stable compared to young couples and thus less likely to be troubled by ED. In addition, with age, 
both the men and their spouse tend to be more understanding with each other, and their physical condition makes them less likely to give more importance to sexual intimacy.

\section{The association between psychological status and age}

The association between psychological status and demographic characteristics was studied, and the age-group was the only demographic characteristic that was found to be significantly associated with psychological scale $(P=0.004)$. This finding was consistent with a study done in men aged 50 years and above. ${ }^{28}$ This finding might suggest that the presence of ED in adult men can indirectly affect their psychological well-being. The fact that men view their ability to erect as a "sense of manhood" might further impair their psychological functions. Thus, they are encouraged to undergo psychoeducation with oral ED therapy to help improve their psychological well-being. ${ }^{2}$

\section{Patient's knowledge about ED and its management} ED is a common problem among men and is thought to affect approximately $10 \%$ of healthy men, and its occurrence is more predominant among those with existing comorbidities. ${ }^{17}$ Study analysis showed that most of the participants perceived that they acquired ED due to diseases (27.8\%), with other reasons being due to aging (18.6\%), medications (12.4\%), and psychological factors $(10.3 \%)$. This analysis was consistent with a finding which stated that more than $80 \%$ of ED patients experienced sexual dysfunction due to vascular diseases such as diabetes, hypertension, and hyperlipidemia. ${ }^{34}$ In addition, a study done in Klang Valley, Malaysia, reported a significant correlation between sexual dysfunction and diabetes mellitus, heart problems as well as prostate problems among men aged more than 50 years. ${ }^{21}$ It is also noted that the ED has a high prevalence among those with diabetes, heart disease, hypertension, and hyperlipidemia. ${ }^{35}$ Furthermore, a recent study reported that diabetic men have a three to four times increased tendency to develop sexual dysfunction compared to the healthy population. ${ }^{36}$

\section{Comorbidities that induce the occurrence of ED}

To date, there is no single etiology that can explain the occurrence of diabetic impotency. ${ }^{37}$ However, several studies have proposed possible mechanism that could lead to sexual dysfunction in diabetic men. This includes the presence of elevated levels of oxygen free radicals and subsequent reduction in nitric oxide (NO) synthesis. Initially, the presence of high blood glucose level in diabetic men will induce the production of advanced glycation end products. This advanced glycation end products is a contributor to the production and elevation level of oxygen free radicals in body, especially in cavernosal tissue. ${ }^{37}$ These free radicals induce oxidative cellular damage, reducing $\mathrm{NO}$ synthesis in cavernosal tissue. A reduction in NO synthesis leads to a reduction in the production of cyclic guanosine monophosphate, which ultimately results in impairment of cavernosal smooth muscle relaxation. ${ }^{37}$ Cavernosal smooth muscle relaxation is very crucial during intercourse as it reduces venous return of blood to the heart, thus enhancing the pool of blood at the penile region that subsequently enhances erection. ${ }^{11}$ Hence, lack of smooth muscle relaxation in diabetic men causes insufficient production of an erection, which significantly affects sexual satisfaction of both men and their partners.

In addition, hyperlipidemia is also a risk factor for ED. ${ }^{34}$ Hyperlipidemia is a condition characterized by an elevation of lipid profile or lipoprotein in blood. ${ }^{38}$ The development of coronary atherosclerosis from the action of low-density lipoprotein is the causative factor for the occurrence of ED. ${ }^{34}$ The presence of this atherosclerosis impairs the blood flow to the penile region, thus causing failure in erection. ${ }^{5}$ Furthermore, hypercholesterolemia may also induce ED by disturbing the normal physiological action of NO, causing impairment in the cavernosal smooth muscle relaxation. ${ }^{34}$ This impairment subsequently results in an inadequate erection, which significantly reduces satisfaction during intercourse.

Hypertension can also induce ED. A recent study reported that the prevalence of sexual dysfunction in hypertensive patient can increase up to approximately $70 \% .{ }^{11}$ The possible mechanism of hypertension-induced ED is mainly due to the presence of atherosclerosis, which induces the thickening of arterial walls. This thickening will subsequently lead to a decrease in blood flow to all parts of the body, including in the penile region, which ultimately leads to ED. ${ }^{5}$ Despite the profound negative effect of ED on men, ED can be advantageous in a way where it serves as a strong indicator of potential cardiovascular disease (CVD) in high-risk men. ${ }^{11}$ The possible explanation is due to the fact that the diameter of penile arteries is one-third of coronary artery diameter. In patients with atherosclerosis, the penile arteries thickened and subsequently lead to a decrease of blood flow to the penis, and thus erection failure. This erection failure usually occurs before the onset of CVD. ${ }^{5}$ In addition, the occurrence of future CVD was also found to be more significant in ED men aged more than 60 years compared to those without ED. ${ }^{11}$ Thus, this shows that lifestyle can indirectly influence 
the occurrence of ED. Healthy lifestyle can delay the onset and progression of ED, while poor lifestyle might accelerate the onset of ED as well as other diseases.

Besides diseases, medications can also induce ED in men. A study reported that medications such as antihypertensives, antiulcers, anxiolytics, antipsychotics, antidepressants, and mood stabilizers can prompt the occurrence of ED. ${ }^{35}$ Antipsychotics and antihypertensive drugs were found to be the most common causes of reported drug-induced ED. ${ }^{11}$ The occurrence was mainly due to the side effects of medication itself. ${ }^{9}$

\section{Patient's knowledge about PDE5 inhibitors therapy}

According to the Guidelines on Male Sexual Dysfunction, oral therapy is the first-line therapy in the management of ED. ${ }^{2}$ Furthermore, the availability of ED oral medications for purchase without prescription makes it the more preferred therapy compared to other alternatives such as a vacuum pump. This might explain the reason why all patients in this study took oral ED therapy, with majority taking sildenafil $50 \mathrm{mg}(25 \%)$.

Upon treatment, the patient's expectation largely influences compliance and self-satisfaction. Unrealistic expectation can lead to noncompliance despite achieving a sufficient erection during intercourse. ${ }^{13}$ From the analysis, it can be seen that most of the participants expect improvement in their penile erections during intercourse $(35.5 \%)$ and total recovery from ED $(33.3 \%)$ upon therapy. According to the recent guideline, the currently available ED therapy can only help in improving erection, but cannot cure it. ${ }^{2}$ In addition, most published clinical trials reported that the effectiveness of oral ED therapy was only approximately $70 \%$, and its effectiveness decreases with the presence of comorbidities such as diabetes mellitus. ${ }^{13}$ Thus, patients who were expecting total recovery were more likely to feel disappointed. The expectation from ED therapy differs mainly because of different meaning they attach to it. ${ }^{31}$ Some people might accept ED as a normal part of aging, while others might find ED as a loss of manliness. Thus, deterioration in sexual function will make them feel "less a man", hence making them more reliant on ED therapy and expecting a total recovery from the treatment. Thus, educating the patient is essential to ensure that patients have proper expectation of treatment results so as to prevent disappointment and discontinuation of therapy.

Besides expectation, adequate knowledge is also essential to ensure effective therapy. Proper administration of medication will ensure optimum efficacy and prevent discontinuation. ${ }^{39}$ Overall, only $45.2 \%$ of patients in this study practiced recommended time administration of oral ED therapy, while others either took the medication wrongly or did not know the recommended time of administration. A study reported approximately $80 \%$ did not respond to sildenafil mainly due to incorrect administration, with approximately $40 \%$ taking sildenafil prior to intercourse and approximately $57 \%$ taking it on a full stomach. ${ }^{40}$ However, it was found that after proper counseling by physicians, approximately one-third of those initially nonsatisfied with sildenafil became satisfied upon treatment with sildenafil. ${ }^{13}$ This shows that physicians play an important role in counseling the patient on appropriate time of administration of medication. Proper understanding will ensure a proper intake of medication by patients, thus enhancing medication efficacy and patient satisfaction.

Patients knowledge about side effects of medication is also important to maintain patient compliance. The overall result showed that $63.4 \%$ of patients knew the side effects of oral ED therapy. According to a recent guideline, the most common side effects experienced by PDE5 inhibitor users are headache and facial flushing. ${ }^{2}$ Although the side effects are generally mild, it may lead to noncompliance and unnecessary hospital visits. ${ }^{41}$ Thus, physicians and pharmacists play an important role in alerting patients about the possible side effects of PDE5 inhibitors. A recent study reported that approximately $95 \%$ of the patients claimed they were not being notified about the side effects of medications. ${ }^{41}$ Furthermore, another study reported approximately 17\% of patients withdraw from ED therapy after experiencing facial flushing and headache. ${ }^{14}$ This shows that educating patients is important to ensure that patients are aware of the possible side effects of their medications and at the same time preventing abrupt discontinuation of medication.

\section{The association between patient's knowledge and socioeconomic status}

The association between patients' knowledge of ED therapy with educational level, occupation as well as monthly income was investigated. Nevertheless, no significant associations were found. Although a study reported that persons with higher educational levels and well-paid jobs had greater control of their own health and lives, ${ }^{24}$ this study reported otherwise. This study visualizes patients' understanding of their therapy as being less likely to be influenced by their educational level, occupation, and household monthly income. This showed that physicians, especially pharmacists, play an important role in educating the patient regardless of their socioeconomic background. A comprehensive 
counseling by using layman terms will improve patient's understanding of their therapy as well as enhancing treatment efficacy and patient satisfaction toward the therapy.

\section{Conclusion}

In conclusion, ED does affect psychological well-being of patients. Besides pharmacological therapy, patient education on ED also plays an important role in the management of ED. Hence, health care professionals, especially pharmacists, should play their role in educating the patient on ED as well as on pharmacological and nonpharmacological therapy of ED. Physicians should also initiate the assessment of erectile function and be more willing to discuss this matter with their patients. This is to prevent ED from being left underdiagnosed. Psychologists should also work hand in hand with other health care professionals in the management of ED. This is based on the fact that untreated psychological problems can further worsen the ED condition as well as impair patients' overall QoL. Hence, physicians, pharmacists, and psychologists need to work hand in hand to ensure optimal therapeutic outcomes of ED therapy among the patients.

\section{Acknowledgment}

The authors thank the University of Malaya, Malaysia (RP024A-14HTM), for financial and technical support.

\section{Disclosure}

The authors report no conflicts of interest in this work.

\section{References}

1. American Psychiatric Association. Diagnostic and Statistical Manual of Mental Disorders (DSM)-5. 5th ed. Arlington, VA: American Psychiatric Association; 2013.

2. Wespes E, Eardley I, Giuliano F, et al. Guidelines on male sexual dysfunction: erectile dysfunction and premature ejaculation. European Association of Urology 2014. Available from: http://uroweb.org/ wp-content/uploads/14-Male-Sexual-Dysfunction_LR.pdf. Accessed November 18, 2013.

3. Safarinejad MR, Hosseini SY. Erectile dysfunction: clinical guidelines. J Urol. 2014;1(3):133-147.

4. Rosen RC. Assessment of sexual dysfunction in patients with benign prostatic hyperplasia. BJU Int. 2006;97:(Suppl 2):29-33.

5. Hood S, Kirby M. Risk factor assessment of erectile dysfunction. BrJ Diabetes Vasc Dis. 2004;4(3):157-161.

6. Latini DM, Penson DF, Colwell HH, et al. Psychological impact of erectile dysfunction: validation of a new health related quality of life measure for patients with erectile dysfunction. J Urol. 2002;168:2086-2091.

7. Raygor R. What Is Psychology? The Science of Psychology. New York, NY: Harcourt College Publishers; 2005:1-32.

8. Ab Rahman AAR, Nabilla AS, Wah YL. Help seeking behaviour among men with erectile dysfunction. J Mens Health. 2011;8(1):594-596.

9. Shabsigh R, Kaufman J, Magee M, et al. Lack of awareness of erectile dysfunction in many men with risk factors for erectile dysfunction. BMC Urol. 2010;10:18-25.

10. Zaman Huri H, Lian Choo T, Sulaiman CZ, Mark R, Abdul Razack AH. Oral drug treatments in patients with erectile dysfunction and multiple comorbidities: a retrospective observational study. BMJ Open. 2014;4:e05381.
11. Shamloul R, Ghanem H. Erectile dysfunction. Lancet. 2013;381: 153-165.

12. Hackett GI. Patient preferences in the treatment of erectile dysfunction: the continuing importance of patient education. Clin Cornerstone Int. 2005;7(1):57-64.

13. Hatzimouratidis K, Hatzichristou DG. Treatment options for erectile dysfunction in patients failing oral drug therapy. EAU. 2004;2:75-83.

14. Sunwoo S, Kim YS, Cho BL, et al. Post-marketing surveillance study of the safety and efficacy of sildenafil prescribed in primary care to erectile dysfunction patients. Int J Impot Res. 2006;17:71-75.

15. Cappelleri JC, Althof SE, Siegel RL, et al. Association between the erectile dysfunction inventory of treatment satisfaction and the self-esteem and relationship questionnaire following treatment with sildenafil citrate for men with erectile dysfunction. Value Health. 2005;8:54-60.

16. Ab Rahman AAR, Nabilla AS, Wah YL. Prevalence of erectile dysfunction in primary care setting Malaysia. J Mens Health. 2011;8(1):50-53.

17. MacDonagh R, Ewings P, Porter T. The effect of erectile dysfunction on quality of life: psychometric testing of a new quality of life measure for patients with erectile dysfunction. J Urol. 2002;167:212-217.

18. San Martin C, Simonelli C, Sonksen J, Schnetzler G, Patel S. Perceptions and opinions of men and women on a man's sexual confidence and its relationship to ED: results of the European Sexual Confidence Survey. Int J Impot Res. 2012;24:234-241.

19. British Medical Association. British National Formulary. 63th ed. London, UK: Pharmaceutical Press; 2012.

20. MIMS. 123rd ed. Petaling Jaya, Selangor; 2010. Availabe from: http:// www.mims.com/malaysia. Accessed November 25, 2013.

21. Low WY, Tong SF, Tan HM. Erectile dysfunction, premature ejaculation and hypogonadism and men's quality of life: an Asian perspective. J Mens Health. 2008;5(4):282-288.

22. Khoo EM, Tan HM, Low WY. Erectile dysfunction and comorbidities in aging men: an urban cross-sectional study in Malaysia. J Sex Med. 2008;5:2925-2934.

23. Tan WS, Ng CJ, Khoo EM, Low WY, Meng HT. The triad of erectile dysfunction, testosterone deficiency syndrome and metabolic syndrome findings from a multi-ethnic Asian men study (The Subang Men's Health Study). Aging Male. 2011;14(4):231-236.

24. Momtaz YA, Hamid TA, Ibrahim R, Akahbar AN. Racial and socioeconomic disparities in sexual activities among older married Malaysians. Arch Gerontol Geriat. 2014;58:51-55.

25. Johannes CB, Araujo AB, Feldman HA, et al. Incidence of erectile dysfunction in men 40 to 69 years old: longitudinal results from the Massachusetts Male Aging Study. J Urol. 2000;163:460-463.

26. Arrington R, Cofrancesco J, Wu AW. Questionnaires to measure sexual quality of life. Qual Life Res. 2004;13:1643-1658.

27. Jeong JY, Lee SK, Kang YW, et al. Relationship between ED and depression among middle-aged and elderly men in Korea: Hallym aging study. Int J Impot Res. 2011;23:227-234.

28. Cheng JYW, Ng EML, Ko JSN. Depressive symptomatology and male sexual function in late life. J Affect Disord. 2007;104:225-229.

29. Araujo AB, Johannes CB, Feldman HA, Derby CA, McKinlay JB. Relation between psychosocial risk factors and incident erectile dysfunction: prospective results from the Massachusetts Male Aging Study. Am J Epidemiol. 2000;152(6):533-541.

30. Dean J, De Boer B, Graziottin A, et al. Effective erectile dysfunction (ED) treatment enables men to enjoy better sex: the importance of erection hardness, psychological well-being, and partner satisfaction. Eur Urol Suppl. 2006;5:761-766.

31. McCabe MP, Matic H. Erectile dysfunction and relationships: views of men with erectile dysfunction and their partners. Sex Relation Ther. 2008;23(1):51-60.

32. Cameron A, Tomlin M. The effect of male erectile dysfunction on the psychosocial, relationship, and characteristics of heterosexual women in the United States. J Sex Marital Ther. 2007;33:135-149.

33. Dunn KM, Croft PR, Hackett GI. Association of sexual problems with social, psychological and physical problems in men and women: a cross sectional population survey. J Epidemiol Community Health. 1999;53: 144-148. 
34. Hackett G. The burden and extent of comorbid conditions in patients with erectile dysfunction. Int J Clin Pract. 2009;63:1123-1126.

35. Seidman SN, Roose SP. The relationship between depression and erectile dysfunction. Curr Psychiatry Rep. 2000;2:201-205.

36. Salonia A, Capogrosso P, Clementi MC, et al. Is erectile dysfunction a reliable indicator of general health status in men? Arab J Urol. 2013;11: 203-211.

37. Thorve VS, Kshirsagar AD, Vyawahare NS, et al. Diabetes-induced erectile dysfunction: epidemiology, pathophysiology and management. J Diabetes Complications. 2011;25:129-136.

38. Hassan BAR. Overview on hyperlipidaemia. J Chromatogr Sep Tech. 2013;4(3):2.
39. Gruenwald I, Shenfeld O, Chen J, et al. Positive effect of counselling and dose adjustment in patients with erectile dysfunction who failed treatment with sildenafil. Eur Urol. 2006;50:134-140.

40. Hatzichristou D, Moysidis K, Apostolidis A, et al. Sildenafil failures may be due to inadequate patient instructions and follow-up: a study on 100 non-responders. Eur Urol. 2005;47:518-523.

41. Bulut H, Tanrikulu G, Dal U, Kapucu S. How much do ED patients know about medication prescribed for them on discharge? A pilot study in Turkey. J Emerg Nurs. 2013;39(3):27-32.

\section{Publish your work in this journal}

Patient Preference and Adherence is an international, peer-reviewed, open access journal that focuses on the growing importance of patient preference and adherence throughout the therapeutic continuum. Patient satisfaction, acceptability, quality of life, compliance, persistence and their role in developing new therapeutic modalities and compounds to optimize clinical outcomes for existing disease states are major areas of interest for the journal. This journal has been accepted for indexing on PubMed Central. The manuscript management system is completely online and includes a very quick and fair peer-review system, which is all easy to use. Visit http://www. dovepress.com/testimonials.php to read real quotes from published authors.

\footnotetext{
Submit your manuscript here: http://www.dovepress.com/patient-preference-and-adherence-journal
} 